\title{
Applications of CYP-450 expression for biomonitoring in environmental health
}

\author{
Ho-Sun Lee $\cdot$ Mihi Yang
}

Received: 8 August 2007 / Accepted: 15 September 2007/Published online: 28 February 2008

(C) The Japanese Society for Hygiene 2008

\begin{abstract}
Cytochrome P450s (CYPs) are one of the first steps in the metabolism of xenobiotics, such as polycyclic aromatic hydrocarbons (PAHs), which are bioactivated into carcinogens. As such, changes in CYP expression are potential biomarkers in human biomonitoring applications. For the proper biomonitoring of environmental toxicants, it is important to understand the biological relevance of each biomarker and the associations among the biomarkers for uses as exposure, effects, and susceptibility biomarkers. Here, we have reviewed various aspects of CYPs for biomonitoring environmental health in terms of the CYP substrates, such as PAHs, aromatic amines, benzene/toluene, and tobacco smoking-related nitrosamines. This review also includes association studies between CYP phenotypical alterations and other exposure, susceptibility, and effect biomarkers. The association studies were mainly performed in CYP gene-transfected cells and noninvasive human biospecies, such as urine and peripheral blood. In conclusion, we suggest that phenotypical alterations in CYPs with exposure to environmental toxicants are useful as susceptibility or effect biomarkers, particularly when the phenotype-related genotypes are unknown.
\end{abstract}

Keywords Association - Biomonitoring - Biomarker . Cytochrome P450s · Exposure - Genotype - Phenotype

H.-S. Lee $\cdot$ M. Yang $(\bowtie)$

Department of Toxicology, College of Pharmacy,

Sookmyung Women's University, 53-12, Chungpa-dong $2 \mathrm{Ka}$,

Yongsan-Ku, Seoul 140-742, Republic of Korea

e-mail: myang@sm.ac.kr

\section{Introduction}

During the past 30 years, biomarker-based approaches have been used in the area of human biomonitoring with the expectation of refining exposure assessment, providing tools for the detection of disease-related changes and their association with environmental and genetic factors and, thereby, facilitating an improved understanding of the etiology of human disease $[1,2]$. The National Institute of Environmental Health Sciences (NIEHS) in the USA, for example, has prioritized research focusing on the development of markers sensitive to environmental exposure, early (preclinical) biological response, and genetic susceptibility as one of its strategic plans for 2006-2011 [3].

In biomonitoring environmental toxicants, each biomarker and the associations among the biomarkers of exposure, effect, response and susceptibility have the potential to provide a better understanding of the biological relevance of the markers themselves. Exposure biomarkers, such as hydroxylated metabolites of toxicants in urine, are used to indicate the internal dose received and to help estimate the exposure amounts of toxicants that have gained entry into the body [4]. Effect biomarkers are measured as the forms that interact with critical targets, such as DNA- and hemoglobin-adducts or cytogenic alterations [for example, chromosomal aberrations (CAs), micronuclei (MN), sister chromatid exchange (SCE), comet/single-cell gel electrophoresis assay, among others]. Susceptibility biomarkers include genetic variations on metabolic enzymes, such as cytochrome P450s (CYPs). Figure 1 summarizes the relations among these biomarkers in terms of risk assessment, which is the ultimate goal of biomonitoring.

CYPs, which are localized in endoplasmic reticulum, are a hemoprotein super-gene family. They are one of the first 


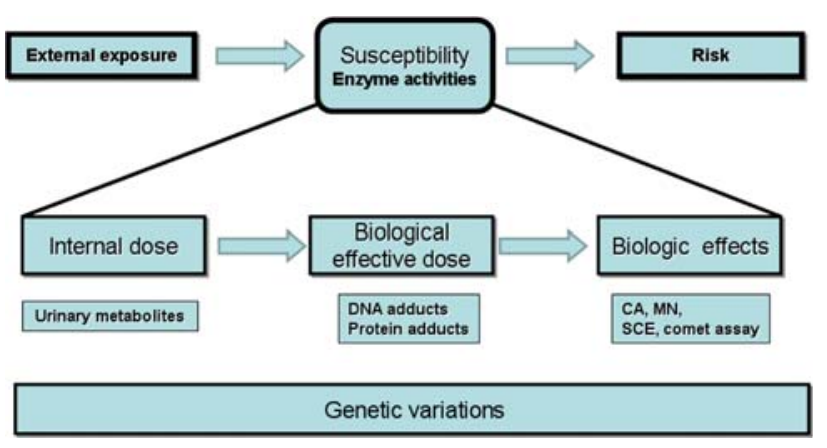

Fig. 1 The procedures of risk assessment with various biomarkers

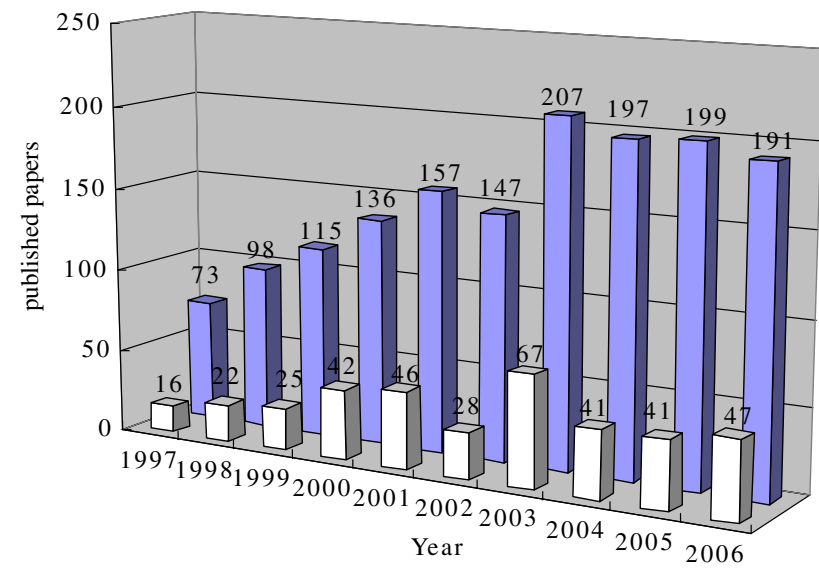

Fig. 2 Published papers dealing with applications of cytochrome P450s (CYPs) in human biomonitoring (1997-2006). Dark bars All applications, light bars applications of CYP polymorphisms in biomonitoring

steps in the metabolism of xenobiotics, such as polycyclic aromatic hydrocarbons (PAHs) and aromatic amines (AAs) that are bioactivated to carcinogens [5, 6]. In addition, expressions of the various CYPs have been broadly used as biomarkers in environmental pollution, drug metabolism, and remedies for pollutants. The increasing number of articles published yearly on web sites dealing with the applications of CYPs in biomonitoring - from 73 in 1997 to 191 in 2006 - are an indication of the increased interest of the scientific community in this super-gene family (Fig. 2).

Various methods, including enzyme assays, immunoassays, and reverse transcriptase (RT)-PCR, have been developed to determine CYP expression. One recent development is a 96-well plate filtration technique for the quick removal of precipitated proteins, followed by fast liquid chromatography/mass spectrometry (LC-MS/MS) analyses for inhibition assays for CYPs [7].

CYPs are known to consist of 99 isozymes in 18 families; there are 583 polymorphic forms in humans, and these polymorphisms have been focused upon due to their induced susceptibility to environmental toxicants [8].
Here, we have categorized four groups of CYP substrates, based on the most widely accepted categorizations in the literature, and reviewed the various applications of CYPs, with special emphasis on their phenotypical alterations, in terms of biomonitoring.

\section{Polycyclic aromatic hydrocarbons}

Although coal processing wastes, petroleum sludge, asphalt, creosote, and other wood preservative wastes contain high levels of PAHs, food, water, air, and tobacco smoke are known as the main or most frequent sources of human exposure to PAHs [9, 10]. A number of epidemiological studies carried out on PAHs have shown that highly exposed workers have an increased cancer risk [11]. The current understanding of the carcinogeneses of PAHs is based predominantly on two complementary mechanisms - the bioproduction of bioactive metabolites, such as diol epoxides, and reactive oxygen species $[12,13]$.

The interaction of PAH ligands with the arylhydrocarbon receptor (AhR) can explain the pathway of CYP induction [14]. The AhR is a ligand-activated transcription factor that acts in concert with the AhR nuclear translocator (ARNT). The nuclear AhR complex, ligand-AhR-ARNT, interacts with consensus dioxin or xenobiotic response elements (DREs/XREs) in the CYP 1 promoter and in promoters of other Ah-responsive genes, and subsequent recruitment of coactivators and general transcription of coactivators and general transcription factors results in the expression of target genes, such as $C Y P 1 A 1,1 A 2$, and $1 B 1$, as well as the genes of other biotransformation enzymes, including $\mathrm{NAD}(\mathrm{P}) \mathrm{H}: q u i n o n e o x i d o r e d u c t a s e$, glutathione $S$-transferase, and UDP-glucuronosyltransferase [15].

In the human lymphocytes, mRNA levels of $A h R$ were found to be positively correlated with those of $C Y P 1 B 1$ and CYP1A1 [16, 17], while mRNA levels of ARNT levels were found to be correlated with only those of CYPIBI [18]. On the other hand, Hayashi et al. [19] reported that mRNA expression levels of CYPIAl were associated with those of $A h R$ and $A R N T$ in smoker's lymphocytes. Protein levels of CYP1A2 were also associated with those of AhR/ARNT in the human LS180 cell lines [20].

Biomonitoring of PAHs has been mainly accomplished by measuring urine metabolites, such as 1-hydroxypyrene (1-OHP), and PAH-related DNA- and protein-adducts. Urinary 1-OHP, a metabolite of pyrene, has been used as a biomarker for determining broad environmental $\mathrm{PAH}$ exposure. An in vitro study showed that CYP1A1, CYP1B1, and CYP1A2 are major metabolizing enzymes involved in the bioproduction of 1-OHP from pyrene [21]. 
Urinary levels of 1-OHP in smokers were correlated to CYP1A2 activity in plasma [22].

Urinary 1-hydroxypyrene- $O$-glucuronide (1-OHPG) is approximately five fold more fluorescent than 1-OHP, leading Strickland et al. [23] to propose that 1-OHPG has the potential to be a sensitive exposure biomarker of PAHs. Pyrene is metabolized into 1-OHPG by CYPs and UDP-glucuronyltransferase (UGT); however, the effects of CYP expression on the bioproduction of 1-OHPG has not yet been thoroughly studied.

Urinary naphthols [2-naphthol (2-NT) more than 1-NT] reflect route-specific exposure to PAHs via air, as compared to 1-OHP, which reflects PAH-total exposure from diet, air, among others [24]. Cho et al. [25] reported that CYP1A2 and CYP3A4 were their most effective in the bioproduction of 1- and 2-NT, respectively, with both CYP2E1 and CYP2A6 being slightly involved in these metabolisms. We previously reported that the CYP2E1*5 polymorphism with $-1019 \mathrm{C}>\mathrm{T}$ affects the levels of urinary naphthols [24]. Compared to the number of 1-OHP studies, biomonitoring studies on 2-NT are relatively rare; consequently, further biomonitoring studies are needed to determine whether the phenotype or genotype of CYP2E1 are susceptibility biomarkers for biomonitoring with 2-NT.

Benzo(a)pyrene $(\mathrm{B} a \mathrm{P})$, a representative carcinogen of PAHs, is oxidized into the chemically reactive diolepoxide (BPDE), which subsequently interacts with DNA to form both stable and unstable adducts of DNA (Fig. 3; [26]). CYP1A1 predominantly mediates BPDE-DNA adducts as a rate-limiting step [27]. In addition, Alexandrov et al. [28] observed a positive correlation between BPDE-DNA adduct levels and microsomal aryl hydrocarbon hydroxylase (AHH) activity in lung tissues. Mollerup et al. [29] reported that CYPIAI and CYPIBI mRNA expression levels were positively associated with bulky-DNA adducts. Furthermore, Piipari et al. [30] found higher levels of PAHDNA adducts in lung tissues of active smokers who had higher protein levels of CYP3A4, and CYP3A5 than others. Degawa et al. [31] also reported positive associations between total DNA adduct levels and immunoreactive amounts of CYP1A1, $-2 \mathrm{C}$, and -3A4 in the larynx tissues of smokers.

In contrast to PAHs, metabolites of nitro-PAHs and their DNA-adducts have been proposed as biomarkers for exposure to petroleum products, such diesel exhaust [32]. In addition, 3-nitrobenzanthrone (3-NBA), a nitro-PAH, is known as an extremely potent mutagen [33-35]. In a study of CYP-expressing V79 cells, Bieler et al. [35] observed that 3-NBA-DNA adduct levels increased with increasing activities of CYP3A4 and CYP oxidoreductase, but not with increasing levels of CYP1A1.

The activity of CYPs, particularly that of the CYP1A subfamily, is known to be involved in the metabolism of aromatic compounds and may modify the effects of the aromatic compounds in terms of DNA oxidation [36]. The
Fig. 3 Metabolic pathway of $B a P$ benzo[ $a]$ pyrene $(B a P)$, benzo[ $a]$ pyrene-7, 8-dihydrodiol-9,10-epoxide $(B P D E)$, glutathione $S$-transferases $(G S T s)$, UDP-glucuronosyltransferases (UGTs), sulfotransferases (SULTS), prostaglandin $\mathrm{H}$ synthase $(P H S)$

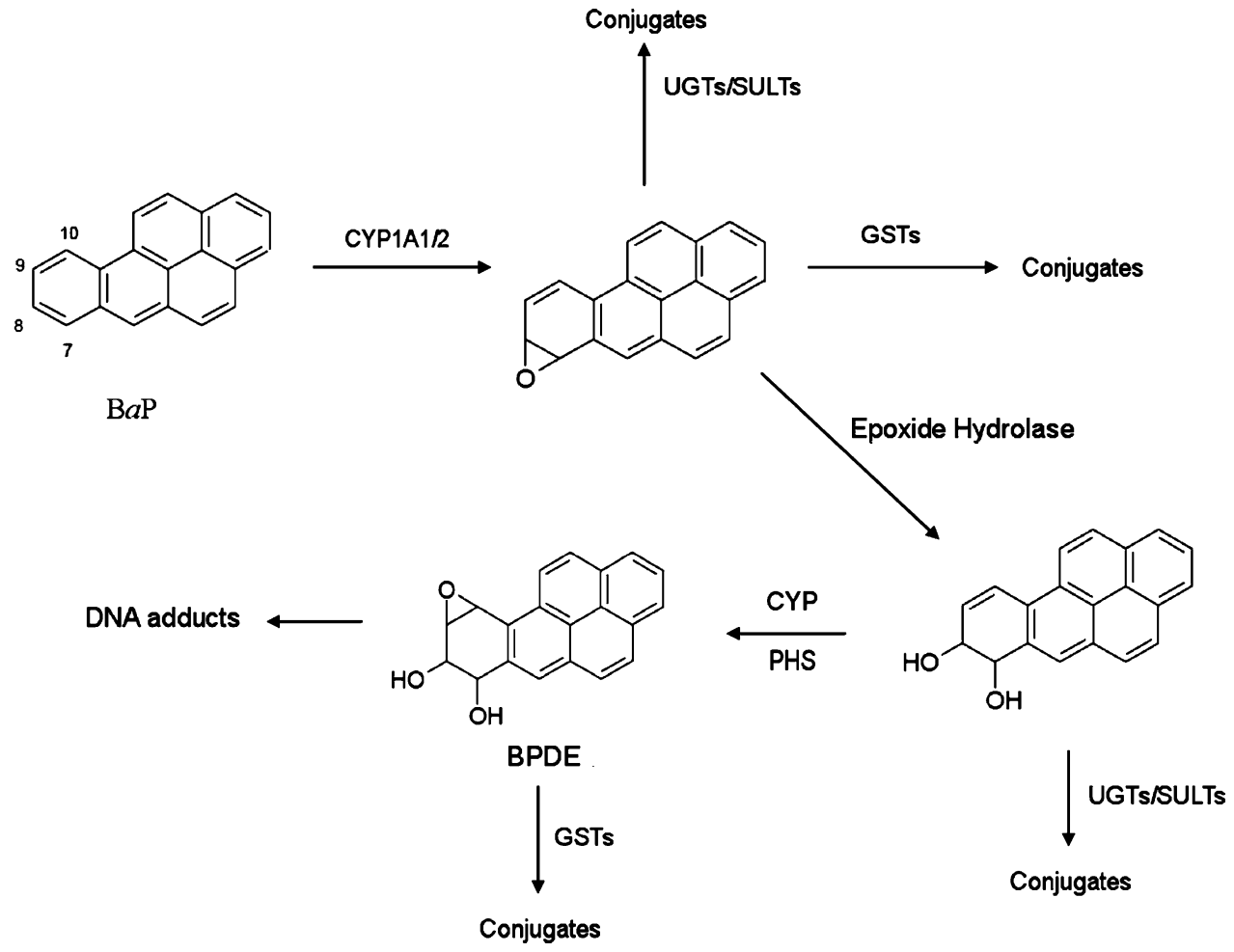


oxidative damage to both DNA and DNA-adducts may be involved in the increased risk of cancer in individuals exposed to PAHs [37, 38]. Quantification of 8-hydroxydeguanosine $(8-\mathrm{OHdG})$ in the urine and blood has been used as a biomarker of oxidative DNA damage [39]. After evaluating three different studies, Poulsen et al. [40] concluded that $8-\mathrm{OHdG}$ was influenced by CYP1A2 activity and that CYP1A2 activity was significantly correlated with 24-h urinary 8-OHdG excretion. In addition, Kim et al. [41] reported correlations between the levels of urinary 1-OHP and $8-\mathrm{OHdG}$ in human leukocytes.

In terms of effect biomarkers, since the 1970s, the conventional cytogenic analysis of peripheral blood lymphocytes has been accepted as a technique suitable for the monitoring of genetic damage in somatic cells [42]. Chromosomal aberrations (CAs), a cytogenic biomarker, are abnormalities in chromosome number or structure. Brandt and Watson [43] proposed that they can function as surrogate endpoints in human peripheral lymphocytes. In a tire plant workers' study, Vodicka et al. [44] found that CAs were somewhat higher in individuals with higher $C Y P 2 E 1$ expression levels in peripheral lymphocytes than in those with relatively lower $C Y P 2 E 1$ expression levels. However, the relationships between CYP expressions and cytogenic alterations have not yet been clarified.

Various biomarkers, or combinations of them, have been used to assess exposure to PAHs. In the case of occupational exposure, urinary excretion of hydroxylated PAH is considered to be the standard for exposure assessment. However, hydroxylated PAH-metabolites in urine can only be used to assess the internal dose following recent exposure to PAHs [45]. Therefore, biomarkers such as DNA-, protein-, and hemoglobin-adducts are preferable for assessing long-term exposure to PAHs. In addition, these biomarkers are subject to a greater variability due to differences in metabolic capacity and genetic polymorphisms in CYPs. The susceptibility towards the induction of CYPs may play an important role in the bioactivation and detoxification of PAHs.

\section{Benzene/toluene}

Benzene is a volatile aromatic hydrocarbon solvent that is widely used in industrial processes. It is absorbed by all routes of exposure, rapidly distributed throughout the body and metabolized to a variety of intermediate compounds, such as benzene oxide, catechol, phenol, hydroquinone, and benzoquinone in several organs, including the liver and bone marrow [46]. The toxicity of benzene in occupational populations has been characterized as either hematotoxicity, including anemia leukopenia, and thrombocytopenia with prolonged exposure to high doses, and irreversible bone marrow damage [47]. Therefore, many attempts have been made to monitor benzene exposure by analyzing blood benzene levels and urinary metabolites, such as urinary trans, trans-muconic acid ( $t, t$-MA) [48].

CYP2E1 has been suggested to be responsible for the metabolism of benzene [49-52]. Sheets et al. [52] also reported that $\mathrm{CYP} 2 \mathrm{E} 1$ and $\mathrm{CYP} 2 \mathrm{~F} 1$ had important roles in the metabolism of benzene in the BEAS2B and A549 human lung cell lines, respectively. In an in vitro study, Tassaneeyakul et al. [53] showed correlations between CYP2E1 activity and the oxidation rates of different benzene metabolites.

Due to the hematotoxicity of benzene, toluene has widely replaced benzene in many industrial processes. Therefore, the biomonitoring of toluene is an important issue in various aspects of occupational health. The major product of the metabolism of toluene by CYPs is benzyl alcohol, which is easily converted to benzoic acid via benzylaldehyde and excreted into the urine as hippuric acid (HA) [53]. $O$-cresol and $p$-cresol are also minor metabolic products of the catalytic action of CYPs on toluene [54]. Nakajima et al. [54] reported that CYP2E1 is the most active enzyme in the formation of benzyl alcohol, followed by CYP2B6, CYP2C8, CYP1A2, and CYP1A1. Epidemiologic studies have shown that the $C Y P 2 E 1 * 5$ polymorphism is associated with toluene metabolism [55, 56]. The most active isozymes in the formation of benzyl alcohol and minor phenolic metabolites are CYP2E1 and CYP1A2, respectively [57]. In a cross-sectional study in the print industry workers, levels of environmental toluene were positively associated with CYP2E1 mRNA levels, while urinary HA levels were negatively correlated with CYP2E1 mRNA levels in peripheral lymphocytes [58]. This dissociation may be due to the capacity of toluene to induce $C Y P 2 E 1$ mRNA expression, whereas HA reflects toluene disposition: Therefore, $C Y P 2 E 1 \mathrm{mRNA}$ level and the toluene exposure ratio (environmental toluene concentration:urinary HA concentration) showed a statistically significant relationship.

In addition, genetic variations in CYPs, particularly the $C Y P 2 E 1 * 5$ genetic polymorphism, have been emphasized as susceptibility biomarkers for benzene or toluene exposure [57, 59]. Therefore, we suggest that both CYP phenotypes and genotypes should be considered for the proper biomonitoring of CYP-substrates. However, phenotypes of CYPs should be used, when phenotypeassociated genetic polymorphisms are unavailable.

\section{Heterocyclic amines and aromatic amines}

Heterocyclic amines (HCAs) originate from the cooking of meats, fish, and poultry and from tobacco smoke, diesel 
exhaust, etc. [60]. A number of epidemiological studies have shown an association between the frequent consumption of well-done cooked meats containing HCAs and elevated risks for colon, prostate, and mammary cancers [61-63]. There are two classes of HCAs formed in cooked meats. One class consists of the $\mathrm{N}$-methyl-2-aminoimidazole moiety, possibly formed through the reaction of pyridine or pyrazines, which are heat-catalyzed degradation products of amino acids, with sugars and creatine. These compounds form in meats heated at $150^{\circ} \mathrm{C}$ or higher, and their formation has been characterized in model systems. The second class of HCAs includes 2-amino-9Hpyridine[2,3-b]indole, 2-amino-3-methyl-9H-pyridole[2,3b]indole, and the glutamic acid and tryptophan pyrolysate mutagens. They are formed in proteins or produced directly from the pyrolysis of these latter two amino acids generated at high temperature $\left(>250^{\circ} \mathrm{C}\right)$ [64]. HCAs are not intrinsically genotoxic; they require metabolic activation, as do most chemical carcinogens. Therefore, HCAs are oxidized to hydroxyamino derivatives by CYPs and then further converted to ester forms. They may eventually produce DNA-adducts through the formation of $\mathrm{N}-\mathrm{C}$ bonds at guanine bases by initially producing highly reactive ester derivates that are known to be bioproduced by four enzyme systems: $N$-acetyltransferase (NAT), sulfotransferase, prolyl tRNA synthetase, and kinases [65]. As HCAs are known to be mainly metabolized by CYP1A2, the rapid CYP1A2 phenotype confers an increased risk of colorectal cancer when combined with the rapid NAT2 phenotype and consumption of well-done meat $[66,67]$. Representative carcinogens of HCAs, 2-amino-3, 8-dimethylimidazo [4, 5$f$ ] quinoxaline (MeIQx), and 2-amino-1-methyl-6-phenylimidazo $[4,5-b]$ pyridine (PhIP), require metabolic activation via $N$-oxidation to convert them into reactive species with genotoxic activity. The $\mathrm{N}$-oxidation of HCAs is catalyzed primarily by hepatic CYP1A2 [68].

Other CYPs, such as CYP1A1, -1B1, and -3A4, are also responsible, to some extent, for the oxidation of the exocyclic primary amino group to a hydroxyamino group [69, 70]. For example, the induction of PhIP-DNA adducts in human microsomes has been related to the activities of CYP1A1, CYP1A2, and CYP3A4 [71].

Aminobiphenyls (ABPs) are one of the groups of aromatic AAs. Of the various ABPs, 4-ABP is classified by IARC [13] as a group 1 carcinogen. ABPs are known to be metabolized into the $N$-hydroxy-ABP intermediates principally in the liver, and these intermediates are precursors to the formation of ABP-DNA adducts in the liver and bladder as well as ABP-hemoglobin ( $\mathrm{Hb})$ adducts in blood [72]. A significant linear relationship was observed between $4-\mathrm{ABP}-\mathrm{Hb}$ adducts and CYP1A2 activity [73]. Therefore, phenotypes with rapid CYP1A2 and slow acetylraters have been implicated in the activation ( $N$-oxidation) and detoxification ( $N$-acethylation) of AAs for human bladder carcinogenesis [73, 74]. Landi et al. [75] reported that a combination of rapid CYP1A2 and slow acetylraters increased the level of $\mathrm{ABP}-\mathrm{Hb}$ adducts.

Stillwell et al. [76] reported that CYP1A2 activity showed a notable influence on total MeIQx excreted in urine (0-12 h). Sinha et al. [77] also reported a relationship between unconjugated MeIQx in 12-h urine samples and CYP1A2 activity, indicating that more MeIQx is converted to the bioactive $N$-hydroxy derivative with higher CYP1A2 activity.

In addition to HCAs and ABPs, nitrosamines are also important chemicals for biomonitoring. Due to the importance of tobacco-specific and carcinogenic nitrosamines, the biomonitoring issues in terms of nitrosamines are reviewed in the following section on tobacco smoking.

\section{Tobacco smoking}

Both active tobacco smoking and passive smoking, such as environmental tobacco smoking (ETS), have been emphasized as major public health factors [78]. Of the 4000 identified chemicals in tobacco smoke, more than 60 are established carcinogens based on IARC assessments [79].

Various biomarkers, such as nicotine, cotinine, 1-OHP, naphthols, have been used as indicators of exposure to tobacco smoking. Compared to nicotine in tobacco, cotinine, a primarily metabolite of nicotine, is stable in body fluids and has a relatively long half-life of approximately $17 \mathrm{~h}$. Therefore, the detection of cotinine is less dependent on the time of sampling than nicotine and other metabolites and has been used an exposure biomarker for active and passive tobacco smoking [78].

CYP2B6, CYP 2C9, CYP 2D6, CYP 2E1, and CYP2A6 are known to biotransfer nicotine into cotinine [80-82]. Extensive empirical evidence indicates that CYP2A6 is the major enzyme involved in nicotine C-oxidation. In addition, numerous epidemiology studies have been carried out with the aim of clarifying whether CYP2A6 is functionally associated with individual variations in the biomonitoring of tobacco smoking [83-85]. We previously reported that CYP2A6*4, the CYP2A6 gene-deleted type, showed lower urinary cotinine levels [86].

The tobacco-specific nitrosamines, $N$-nitrosonornicotine (NNN) and 4-(methylnitrosamino)-1-(3-pyridyl)-1-butanone (NNK), have been known to play a role in human tobacco-related cancers. Fujita and Kamataki [87] reported the involvement of CYPs in the metabolic activation of tobacco-related $N$-nitrosamines in $C Y P$-transfected cells. CYP3A4 and CYP2E1 were linked to the activation of 


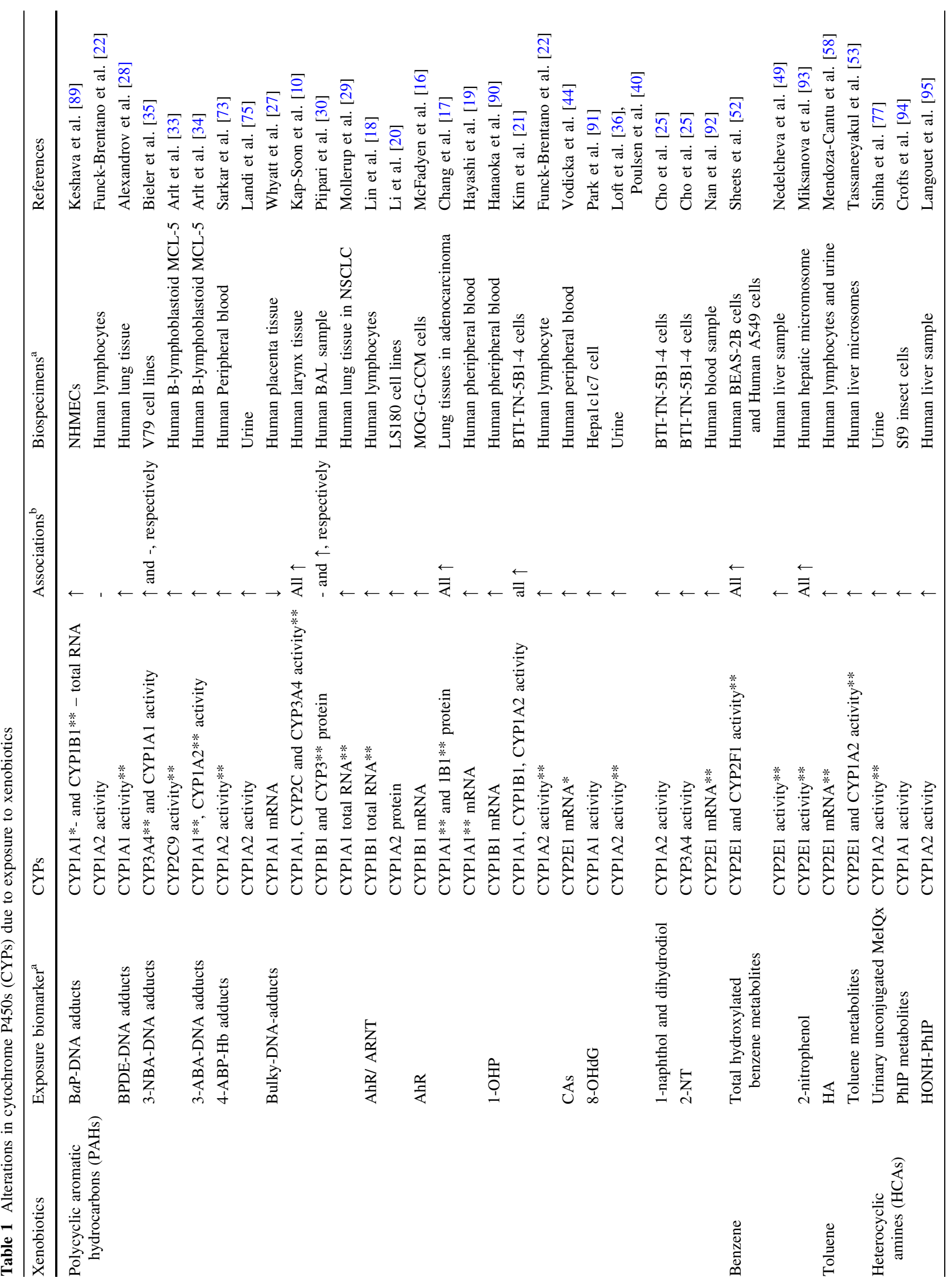




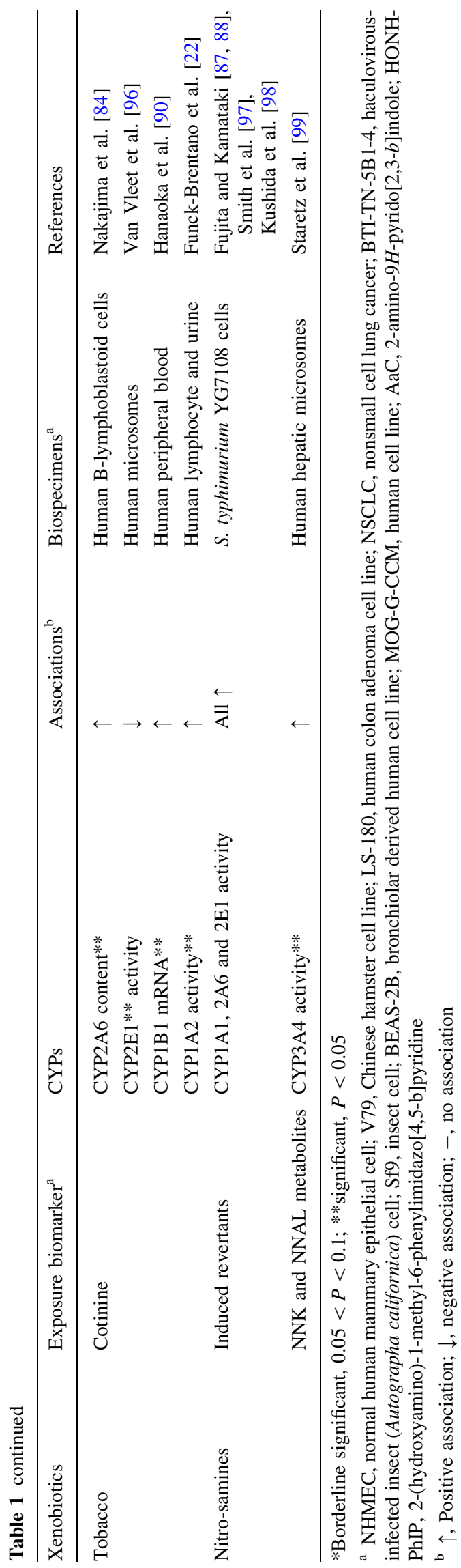

NNN and $N$-nitrosodemetylamine (NDMA) in human fibroblasts [87], while CYP1A1 showed tobacco smokinginducible expression in the human placenta [88].

Therefore, levels of urinary cotinine and nitrosamines are related to the expression of CYPs, particularly CYP2A6. When the aim is to perform proper exposure monitoring of active and passive tobacco smoking, alterations of CYP2A6 expression should be considered.

\section{Conclusion}

In this review, we have summarized phenotypical alterations to CYPs resulting from the exposure to xenobiotics (see Table 1). The capacity in inducing CYPs may play an important role between activation of the xenobiotics and subsequent risk for developing chemically induced diseases. In addition, assessment of the set of putative CYPs will allow the identification of susceptible individuals or subgroups. However, there remains some discrepancies in reports on the associations between CYP expression and exposure or effect biomarkers. In addition, various characteristics of CYPs, such as their broad spectrum or the overlapping of substrates, induce combined effects of CYP isozymes during biomonitoring.

In conclusion, we suggest that phenotypical alterations in CYPs with exposure to environmental toxicants are preferable as susceptibility or effect biomarkers, particularly when phenotype-related genotypes are unknown.

Acknowledgments This work was supported by the SRC program of KOSEF (Research Center for Women's Diseases).

\section{References}

1. Kyrtopoulos SA. Biomarkers in environmental carcinogenesis research: striving for a new momentum. Toxicol Lett. 2006;162(1):3-15.

2. Angerer J, Ewers U, Wilhelm M. Human biomonitoring: state of the art. Int J Hyg Environ Health. 2007;210(3-4):201-28.

3. National Institutes of Environmental Health Sciences (NIEHS) Available at: http://www.Nieh.nih.gov/external/2006.

4. Bostrom CE, Gerde P, Hanberg A, Jernstrom B, Johansson C, Kyrklund $\mathrm{T}$, et al. Cancer risk assessment, indicators, and guidelines for polycyclic aromatic hydrocarbons in the ambient air. Environ Health Perspect. 2002;110[Suppl 3]:451-88.

5. Wenzlaff AS, Cote ML, Bock CH, Land SJ, Santer SK, Schwartz DR, et al. CYP1A1 and CYP1B1 polymorphisms and risk of lung cancer among never smokers: a population-based study. Carcinogenesis. 2005;26(12):2207-12.

6. Kiyohara C, Otsu A, Shirakawa T, Fukuda S, Hopkin JM. Genetic polymorphisms and lung cancer susceptibility: a review. Lung Cancer. 2002;37(3):241-256.

7. Yao M, Zhu M, Sinz MW, Zhang H, Humphreys WG, Rodrigues $\mathrm{AD}$, et al. Development and full validation of six inhibition assays for five major cytochrome P450 enzymes in human liver microsomes using an automated 96-well microplate incubation 
format and LC-MS/MS analysis. $\mathrm{J}$ Pharm Biomed Anal. 2007;44(1):211-23.

8. Human Cytochrome P450 (CYP) Allele Nomenclature Committee. Available at: http://www.imm.ki.se/CYPalleles.

9. Goldman R, Enewold L, Pellizzari E, Beach JB, Bowman ED, Krishnan SS, et al. Smoking increases carcinogenic polycyclic aromatic hydrocarbons in human lung tissue. Cancer Res. 2001;61(17):6367-71.

10. Kap-Soon N, Do-Youn L, Hak CJ, Joo WA, Lee E, Chan-Wha K. Protein biomarkers in the plasma of workers occupationally exposed to polycyclic aromatic hydrocarbons. Proteomics. 2004;4(11):3505-33.

11. National Environment Protection Council (NEPC) (2003). Impact Statement for the National Environment Protection (Air Toxics) Measure. Government of Australia. Available at: http://www. nepc.gov.au.

12. International Agency for Research on Cancer (IARC). Monographs on the evaluation of the carcinogenic risks to human overall evaluations of carcinogenicity: an updating of IARC monographs (1-42). World Health Organization, Geneva. 1990.

13. International Agency for Research on Cancer (IARC). Monographs on the evaluation of the carcinogenic risks to human, vol 92. World Health Organization, Geneva. 2007.

14. Safe S. Molecular biology of the Ah receptor and its role in carcinogenesis. Toxicol Lett. 2001;120(1-3):1-7.

15. Vrzal R, Ulrichova J, Dvorak Z. Aromatic hydrocarbon receptor status in the metabolism of xenobiotics under normal and pathophysiological conditions. Biomed Paper. 2004;148(1):3-10.

16. McFadyen MC, Rooney PH, Melvin WT, Murray GI. Quantitative analysis of the Ah receptor/cytochrome P450 CYP1B1/ CYP1A1 signalling pathway. Biochem Pharmacol. 2003;65(10): 1663-74.

17. Chang JT, Chang H, Chen PH, Lin SL, Lin P. Requirement of aryl hydrocarbon receptor overexpression for CYP1B1 up-regulation and cell growth in human lung adenocarcinomas. Clin Cancer Res. 2007;13(1):38-45.

18. Lin P, Hu SW, Chang TH. Correlation between gene expression of aryl hydrocarbon receptor (AhR), hydrocarbon receptor nuclear translocator (Arnt), cytochromes P4501A1 (CYP1A1) and 1B1 (CYP1B1), and inducibility of CYP1A1 and CYP1B1 in human lymphocytes. Toxicol Sci. 2003;71(1):20-6.

19. Hayashi S, Watanabe J, Nakachi K, Eguchi H, Gotoh O, Kawajiri $\mathrm{K}$. Interindividual difference in expression of human $\mathrm{Ah}$ receptor and related P450 genes. Carcinogenesis. 1994;15(5):801-6.

20. Li W, Harper PA, Tang BK, Okey AB. Regulation of cytochrome P450 enzymes by aryl hydrocarbon receptor in human cells: CYP1A2 expression in the LS180 colon carcinoma cell line after treatment with 2,3,7,8-tetrachlorodibenzo-p-dioxin or 3-methylcholanthrene. Biochem Pharmacol. 1998;56(5):599-612.

21. Kim YD, Todoroki H, Oyama T, Isse T, Matsumoto A, Yamaguchi $\mathrm{T}$, et al. Identification of cytochrome P450 isoforms involved in 1-hydroxylation of pyrene. Environ Res. 2004;94(3): 262-6.

22. Funck-Brentano C, Raphael M, Lafontaine M, Arnould JP, Verstuyft C, Lebot M, et al. Effects of type of smoking (pipe, cigars or cigarettes) on biological indices of tobacco exposure and toxicity. Lung Cancer. 2006;54(1):11-8.

23. Strickland PT, Kang D, Bowman ED, Fitzwilliam A, Downing $\mathrm{TE}$, Rothman N, et al. Identification of 1-hydroxypyrene glucuronide as a major pyrene metabolite in human urine by synchronous fluorescence spectroscopy and gas chromatographymass spectrometry. Carcinogenesis. 1994;15(3):483-7.

24. Yang M, Koga M, Katoh T, Kawamoto T. A study for the proper application of urinary naphthols, new biomarkers for airborne polycyclic aromatic hydrocarbons. Arch Environ Contam Toxicol. 1999;36(1):99-108.
25. Cho TM, Rose RL, Hodgson E. In vitro metabolism of naphthalene by human liver microsomal cytochrome P450 enzymes. Drug Metab Dispos. 2006;34(1):176-83.

26. Nakajima T, Elovaara E, Anttila S, Hirvonen A, Camus AM, Hayes JD, et al. Expression and polymorphism of glutathione S-transferase in human lungs: risk factors in smoking-related lung cancer. Carcinogenesis. 1995;16(4):707-11.

27. Whyatt RM, Bell DA, Jedrychowski W, Santella RM, Garte SJ, Cosma G, et al. Polycyclic aromatic hydrocarbon-DNA adducts in human placenta and modulation by CYP1A1 induction and genotype. Carcinogenesis. 1998;19(8):1389-92.

28. Alexandrov K, Rojas M, Geneste O, Castegnaro M, Camus AM, Petruzzelli S, et al. An improved fluorometric assay for dosimetry of benzo(a)pyrene diol-epoxide-DNA adducts in smokers' lung: comparisons with total bulky adducts and aryl hydrocarbon hydroxylase activity. Cancer Res. 1992;52(22):6248-53.

29. Mollerup S, Berge G, Baera R, Skaug V, Hewer A, Phillips DH, et al. Sex differences in risk of lung cancer: Expression of genes in the PAH bioactivation pathway in relation to smoking and bulky DNA adducts. Int J Cancer. 2006;119(4):741-4.

30. Piipari R, Savela K, Nurminen T, Hukkanen J, Raunio H, Hakkola J, et al. Expression of CYP1A1, CYP1B1 and CYP3A, and polycyclic aromatic hydrocarbon-DNA adduct formation in bronchoalveolar macrophages of smokers and non-smokers. Int $\mathbf{J}$ Cancer. 2000;86(5):610-6.

31. Degawa M, Stern SJ, Martin MV, Guengerich FP, Fu PP, Ilett $\mathrm{KF}$, et al. Metabolic activation and carcinogen-DNA adduct detection in human larynx. Cancer Res. 1994;54(18):4915-9.

32. Toriba A, Kitaoka H, Dills RL, Mizukami S, Tanabe K, Takeuchi $\mathrm{N}$, et al. Identification and quantification of 1-nitropyrene metabolites in human urine as a proposed biomarker for exposure to diesel exhaust. Chem Res Toxicol. 2007;20(7):999-1007.

33. Arlt VM, Stiborova M, Hewer A, Schmeiser HH, Phillips DH. Human enzymes involved in the metabolic activation of the environmental contaminant 3-nitrobenzanthrone: evidence for reductive activation by human NADPH:cytochrome p450 reductase. Cancer Res. 2003;63(11):2752-61.

34. Arlt VM, Hewer A, Sorg BL, Schmeiser HH, Phillips DH, Stiborova M. 3-aminobenzanthrone, a human metabolite of the environmental pollutant 3-nitrobenzanthrone, forms DNA adducts after metabolic activation by human and rat liver microsomes: evidence for activation by cytochrome P450 1A1 and P450 1A2. Chem Res Toxicol. 2004;17(8):1092-101.

35. Bieler CA, Arlt VM, Wiessler M, Schmeiser HH. DNA adduct formation by the environmental contaminant 3-nitrobenzanthrone in V79 cells expressing human cytochrome P450 enzymes. Cancer Lett. 2003;200(1):9-18.

36. Loft S, Poulsen HE, Vistisen K, Knudsen LE. Increased urinary excretion of 8-oxo-2'-deoxyguanosine, a biomarker of oxidative DNA damage, in urban bus drivers. Mutat Res. 1999;441(1): $11-9$.

37. Marczynski B, Rihs HP, Rossbach B, Holzer J, Angerer J, Scherenberg M, et al. Analysis of 8-oxo-7,8-dihydro-2'-deoxyguanosine and DNA strand breaks in white blood cells of occupationally exposed workers: comparison with ambient monitoring, urinary metabolites and enzyme polymorphisms. Carcinogenesis. 2002;23(2):273-81.

38. Zhang J, Ichiba M, Hanaoka T, Pan G, Yamano Y, Hara K, et al. Leukocyte 8-hydroxydeoxyguanosine and aromatic DNA adduct in coke-oven workers with polycyclic aromatic hydrocarbon exposure. Int Arch Occup Environ Health. 2003;76(7): 499-504.

39. Kasai H, Crain PF, Kuchino Y, Nishimura S, Ootsuyama A, Tanooka H. Formation of 8-hydroxyguanine moiety in cellular DNA by agents producing oxygen radicals and evidence for its repair. Carcinogenesis. 1986;7(11):1849-51. 
40. Poulsen HE, Loft S, Prieme H, Vistisen K, Lykkesfeldt J, Nyyssonen $\mathrm{K}$, et al. Oxidative DNA damage in vivo: relationship to age, plasma antioxidants, drug metabolism, glutathione-S-transferase activity and urinary creatinine excretion. Free Radic Res. 1998;29(6):565-71.

41. Kim YD, Lee CH, Nan HM, Kang JW, Kim H. Effects of genetic polymorphisms in metabolic enzymes on the relationships between 8-hydroxydeoxyguanosine levels in human leukocytes and urinary 1-hydroxypyrene and 2-naphthol concentrations. J Occup Health. 2003;45(3):160-7.

42. Rossner P, Boffetta P, Ceppi M, Bonassi S, Smerhovsky Z, Landa $\mathrm{K}$, et al. Chromosomal aberrations in lymphocytes of healthy subjects and risk of cancer. Environ Health Perspect. 2005;113(5): 517-20.

43. Brandt HC, Watson WP. Monitoring human occupational and environmental exposures to polycyclic aromatic compounds. Ann Occup Hyg. 2003;47(5):349-78.

44. Vodicka P, Kumar R, Stetina R, Musak L, Soucek P, Haufroid V, et al. Markers of individual susceptibility and DNA repair rate in workers exposed to xenobiotics in a tire plant. Environ Mol Mutagen. 2004;44(4):283-92.

45. Jongeneelen FJ, Anzion RB, Scheepers PT, Bos RP, Henderson PT, Nijenhuis EH, et al. 1-Hydroxypyrene in urine as a biological indicator of exposure to polycyclic aromatic hydrocarbons in several work environments. Ann Occup Hyg. 1988;32(1):35-43.

46. Martinez-Velazquez M, Maldonado V, Ortega A, MelendezZajgla J, Albores A. Benzene metabolites induce apoptosis in lymphocytes. Exp Toxicol Pathol. 2006;58(1):65-70.

47. Snyder R, Hedli CC. An overview of benzene metabolism. Environ Health Perspect. 1996;104(Suppl 6):1165-71.

48. Fustinoni S, Consonni D, Campo L, Buratti M, Colombi A, Pesatori AC, et al. Monitoring low benzene exposure: comparative evaluation of urinary biomarkers, influence of cigarette smoking, and genetic polymorphisms. Cancer Epidemiol Biomarkers Prev. 2005;14(9):2237-44.

49. Nedelcheva V, Gut I, Soucek P, Tichavska B, Tynkova L, Mraz J, et al. Metabolism of benzene in human liver microsomes: individual variations in relation to CYP2E1 expression. Arch Toxicol. 1999;73(1):33-40.

50. Powley MW, Carlson GP. Hepatic and pulmonary microsomal benzene metabolism in CYP2E1 knockout mice. Toxicology. 2001;169(3):187-94.

51. Powley MW, Carlson GP. Cytochrome P450 isozymes involved in the metabolism of phenol, a benzene metabolite. Toxicol Lett. 2001;125(1-3):117-23.

52. Sheets PL, Yost GS, Carlson GP. Benzene metabolism in human lung cell lines BEAS-2B and A549 and cells overexpressing CYP2F1. J Biochem Mol Toxicol. 2004;18(2):92-9.

53. Tassaneeyakul W, Birkett D, Edwards J, Veronese M, Tassaneeyakul W, Tukey R, et al. Human cytochrome P450 isoform specificity in the regioselective metabolism of toluene and o-, and p-xylene. Pharmacology. 1996;276(1):101-8.

54. Nakajima T, Wang RS, Elovaara E, Gonzalez FJ, Gelboin HV, Raunio H, et al. Toluene metabolism by cDNA-expressed human hepatic cytochrome P450. Biochem Pharmacol. 1997;53(3): 271-7.

55. Kawamoto T, Koga M, Murata K, Matsuda S, Kodama Y. Effects of ALDH2, CYP1A1, and CYP2E1 genetic polymorphisms and smoking and drinking habits on toluene metabolism in humans. Toxicol Appl Pharmacol. 1995;133(2):295-304.

56. Yim H, Park CY, Roh YM, Lee KS, Lee JM, Lee WC, et al. Effects of genetic factor, life styles, and diet on urinary hippuric acid excretion in toluene exposed workers. Korean J Occup Environ Med. 2000; 12(3):405-20.

57. Kim H, Wang RS, Elovaara E, Raunio H, Pelkonen O, Aoyama $\mathrm{T}$, et al. Cytochrome $\mathrm{P} 450$ isozymes responsible for the metabolism of toluene and styrene in human liver microsomes. Xenobiotica. 1997;27(7):657-65.

58. Mendoza-Cantu A, Castorena-Torres F, Bermudez de Leon M, Cisneros B, Lopez-Carrillo L, Rojas-Garcia AE, et al. Occupational toluene exposure induces cytochrome P450 2E1 mRNA expression in peripheral lymphocytes. Environ Health Perspect. 2006;114(4):494-9.

59. Kim SY, Choi JK, Cho YH, Chung EJ, Paek D, Chung HW. Chromosomal aberrations in workers exdosed to low levels of benzene: association with genetic polymorphisms. Pharmacogenetics. 2004;14(7):453-63.

60. Cross AJ, Sinha R. Meat-related mutagens/carcinogens in the etiology of colorectal cancer. Environ Mol Mutagen. 2004;44(1): $44-55$.

61. Dai Q, Shu XO, Jin F, Gao YT, Ruan ZX, Zheng W. Consumption of animal foods, cooking methods, and risk of breast cancer. Cancer Epidemiol Biomarkers Prev. 2002;11(9):801-8.

62. Sinha R. An epidemiologic approach to studying heterocyclic amines. Mutat Res. 2002;506-507:197-204.

63. Rohrmann S, Platz EA, Kavanaugh CJ, Thuita L, Hoffman SC, Helzlsouer KJ. Meat and dairy consumption and subsequent risk of prostate cancer in a US cohort study. Cancer Causes Control. 2007;18(1):41-50.

64. Turesky RJ. Formation and biochemistry of carcinogenic heterocyclic aromatic amines in cooked meats. Toxicol Lett. 2007;168(3):219-27.

65. Sugimura T, Wakabayashi K, Nakagama H, Nagao M. Heterocyclic amines: Mutagens/carcinogens produced during cooking of meat and fish. Cancer Sci. 2004;95(4):290-9.

66. Lang NP, Butler MA, Massengill J, Lawson M, Stotts RC, Hauer-Jensen M, et al. Rapid metabolic phenotypes for acetyltransferase and cytochrome P4501A2 and putative exposure to food-borne heterocyclic amines increase the risk for colorectal cancer or polyps. Cancer Epidemiol Biomarkers Prev. 1994;3(8): 675-82.

67. Le Marchand L, Hankin JH, Wilkens LR, Pierce LM, Franke A, Kolonel LN, et al. Combined effects of well-done red meat, smoking, and rapid $\mathrm{N}$-acetyltransferase 2 and CYP1A2 phenotypes in increasing colorectal cancer risk. Cancer Epidemiol Biomarkers Prev. 2001;10(12):1259-66.

68. Kim D, Guengerich FP. Cytochrome P450 activation of arylamines and heterocyclic amines. Annu Rev Pharmacol Toxicol. 2005;45:27-49.

69. Yamazoe Y, Shimada M, Kamataki T, Kato R. Microsomal activation of 2-amino-3-methylimidazo[4,5-f]quinoline, a pyrolysate of sardine and beef extracts, to a mutagenic intermediate. Cancer Res. 1983;43(12 Pt 1):5768-74.

70. Hammons GJ, Milton D, Stepps K, Guengerich FP, Tukey RH, Kadlubar FF. Metabolism of carcinogenic heterocyclic and aromatic amines by recombinant human cytochrome P450 enzymes. Carcinogenesis. 1997;18(4):851-4.

71. Baranczewski P, Moller L. Relationship between content and activity of cytochrome P450 and induction of heterocyclic amine DNA adducts in human liver samples in vivo and in vitro. Cancer Epidemiol Biomarkers Prev. 2004;13(6):1071-8.

72. Tsuneoka Y, Dalton TP, Miller ML, Clay CD, Shertzer HG, Talaska G, et al. 4-aminobiphenyl-induced liver and urinary bladder DNA adduct formation in Cyp1a2(-/-) and Cyp1a2(+/+) mice. J Natl Cancer Inst. 2003;95(16):1227-37.

73. Sarkar M, Stabbert R, Kinser RD, Oey J, Rustemeier K, von Holt $\mathrm{K}$, et al. CYP1A2 and NAT2 phenotyping and 3-aminobiphenyl and 4-aminobiphenyl hemoglobin adduct levels in smokers and non-smokers. Toxicol Appl Pharmacol. 2006;213(3):198-206.

74. Talaska G. Aromatic amines, human urinary bladder cancer: exposure sources and epidemiology. J Environ Sci Health C Environ Carcinog Ecotoxicol Rev. 2003;21(1):29-43. 
75. Landi MT, Zocchetti C, Bernucci I, Kadlubar FF, Tannenbaum S, Skipper P, et al. Cytochrome P4501A2: enzyme induction and genetic control in determining 4-aminobiphenyl-hemoglobin adduct levels. Cancer Epidemiol Biomarkers Prev. 1996;5(9): 693-8.

76. Stillwell WG, Kidd LC, Wishnok JS, Tannenbaum SR, Sinha R. Urinary excretion of unmetabolized, phase II conjugates of 2-amino-1-methyl-6-phenylimidazo[4,5-b]pyridine and 2-amino3,8-dimethylimidazo[4,5-f]quinoxaline in humans: relationship to cytochrome P4501A2 and $\mathrm{N}$-acetyltransferase activity. Cancer Res. 1997;57(16):3457-64.

77. Sinha R, Rothman N, Mark SD, Murray S, Brown ED, Levander $\mathrm{OA}$, et al. Lower levels of urinary 2-amino-3,8-dimethylimidazo[4,5-f]-quinoxaline (MeIQx) in humans with higher CYP1A2 activity. Carcinogenesis. 1995;16(11):2859-61.

78. Yang M, Pyo MY. Molecular epidemiology of lung cancer in female passive smokers. J Environ Sci Health C Environ Carcinog Ecotoxicol Rev. 2005;23(1):75-97.

79. Hecht SS. Cigarette smoking, lung cancer: chemical mechanisms, approaches to prevention. Lancet Oncol. 2002;3(8):461-9.

80. Cashman R, Park Z, Yang S, Wrighton P, Benowitz N. Metabolism of nicotine by human liver microsomes: stereoselective formation of trans-nicotine $\mathrm{N}^{\prime}$-oxide. Chem Res Toxicol. 1992;5:639-46.

81. Flammang A, Gelboin H, AoyamaT, Gonzalez F, McCoy G. Nicotine metabolism by cDNA expressed human cytochrome P450. Biochem Arch. 1992;8:1-8.

82. McCracken $\mathrm{N}$, Cholerton S, Idle J. Nicotine formation by cDNAexpressed human cytochrome P450. Med Sci Res. 1992;20: 877-8.

83. Kitagawa K, Kunugita N, Katoh T, Yang M, Kawamoto T. The significance of the homozygous CYP2A6 deletion on nicotine metabolism: a new genotyping method of CYP2A6 using a single PCR-RFLP. Biochem Biophys Res Commun. 1999;262(1): 146-51.

84. Nakajima M, Yamagishi S, Yamamoto H, Yamamoto T, Kuroiwa $\mathrm{Y}$, Yokoi T. Deficient cotinine formation from nicotine is attributed to the whole deletion of the CYP2A6 gene in humans. Clin Pharmacol Ther. 2000;67(1):57-69.

85. Rao Y, Hoffmann E, Zia M, Bodin L, Zeman M, Sellers EM, et al. Duplications and defects in the CYP2A6 gene: identification, genotyping, and in vivo effects on smoking. Mol Pharmacol. 2000;58(4):747-55.

86. Yang M, Kunugita N, Kitagawa K, Kang SH, Coles B, Kadlubar $\mathrm{FF}$, et al. Individual differences in urinary cotinine levels in Japanese smokers: relation to genetic polymorphism of drugmetabolizing enzymes. Cancer Epidemiol Biomarkers Prev. 2001;10(6):589-93.

87. Fujita K, Kamataki T. Predicting the mutagenicity of tobaccorelated N-nitrosamines in humans using 11 strains of Salmonella typhimurium YG7108, each coexpressing a form of human cytochrome $\mathrm{P} 450$ along with NADPH-cytochrome $\mathrm{P} 450$ reductase. Environ Mol Mutagen. 2001;38(4):339-46.
88. Fujita K, Kamataki T. Role of human cytochrome P450 (CYP) in the metabolic activation of $\mathrm{N}$-alkylnitrosamines: application of genetically engineered Salmonella typhimurium YG7108 expressing each form of CYP together with human NADPHcytochrome P450 reductase. Mutat Res. 2001;483(1-2):35-41.

89. Keshava C, Divi RL, Whipkey DL, Frye BL, McCanlies E, Kuo $\mathrm{M}$, et al. Induction of CYP1A1 and CYP1B1 and formation of carcinogen-DNA adducts in normal human mammary epithelial cells treated with benzo[a]pyrene. Cancer Lett. 2005;221(2): 213-24.

90. Hanaoka T, Yamano Y, Pan G, Hara K, Ichiba M, Zhang J, et al. Cytochrome P450 1B1 mRNA levels in peripheral blood cells and exposure to polycyclic aromatic hydrocarbons in Chinese coke oven workers. Sci Total Environ. 2002;296(1-3):27-33.

91. Park JY, Shigenaga MK, Ames BN. Induction of cytochrome P4501A1 by 2, 3, 7, 8-tetrachlorodibenzo-p-dioxin or indolo(3,2b)carbazole is associated with oxidative DNA damage. Proc Natl Acad Sci USA. 1996;93(6):2322-7.

92. Nan HM, Kim H, Lim HS, Choi JK, Kawamoto T, Kang JW, et al. Effects of occupation, lifestyle and genetic polymorphisms of CYP1A1, CYP2E1, GSTM1 and GSTT1 on urinary 1-hydroxypyrene and 2-naphthol concentrations. Carcinogenesis. 2001;22(5):787-93.

93. Miksanova M, Sulc M, Rydlova H, Schmeiser HH, Frei E, Stiborova M. Enzymes involved in the metabolism of the carcinogen 2-nitroanisole: evidence for its oxidative detoxication by human cytochromes P450. Chem Res Toxicol. 2004;17(5):663-71.

94. Crofts FG, Sutter TR, Strickland PT. Metabolism of 2-amino-1methyl-6-phenylimidazo[4,5-b]pyridine by human cytochrome P4501A1, P4501A2 and P4501B1. Carcinogenesis. 1998;19(11): 1969-73.

95. Langouet S, Paehler A, Welti DH, Kerriguy N, Guillouzo A, Turesky RJ. Differential metabolism of 2-amino-1-methyl-6phenylimidazo[4,5-b]pyridine in rat and human hepatocytes. Carcinogenesis. 2002;23(1):115-22.

96. Van Vleet TR, Bombick DW, Coulombe RA Jr. Inhibition of human cytochrome P450 2E1 by nicotine, cotinine, and aqueous cigarette tar extract in vitro. Toxicol Sci. 2001;64(2):185-91.

97. Smith TJ, Liao A, Wang LD, Yang GY, Starcic S, Philbert MA, et al. Characterization of xenobiotic-metabolizing enzymes and nitrosamine metabolism in the human esophagus. Carcinogenesis. 1998;19(4):667-72.

98. Kushida H, Fujita K, Suzuki A, Yamada M, Endo T, Nohmi T, et al. Metabolic activation of $\mathrm{N}$-alkylnitrosamines in genetically engineered Salmonella typhimurium expressing CYP2E1 or CYP2A6 together with human NADPH-cytochrome P450 reductase. Carcinogenesis. 2000;21(6):1227-32.

99. Staretz ME, Murphy SE, Patten CJ, Nunes MG, Koehl W, Amin $\mathrm{S}$, et al. Comparative metabolism of the tobacco-related carcinogens benzo[a]pyrene, 4-(methylnitrosamino)-1-(3-pyridyl)-1butanone, 4-(methylnitrosamino)-1-(3-pyridyl)-1-butanol, and N'- nitrosonornicotine in human hepatic microsomes. Drug Metab Dispos. 1997;25(2):154-62. 